\title{
Persecución y muerte violenta de los profetas de Israel
}

\author{
Rafael de Sivatte, \\ Centro de Reflexión Teológica, \\ San Salvador.
}

En este año en que conmemoramos el décimo aniversario de la muerte martirial de los seis jesuitas, Julia Elba y Celina, asesinados el 16 de noviembre de 1989, en que iniciamos las celebraciones del vigésimo aniversario del martirio de Monseñor Romero y en que recordamos —al inicio del tercer milenio- a todos los mártires de las iglesias, es importante iluminar dichos martirios con la lectura de la palabra de Dios.

En este artículo nos vamos a centrar en lo que dice el Antiguo Testamento sobre el destino de los profetas a quienes hoy llamarfamos "mártires", pues su vida y muerte es semejante a la de Jesús y a la de muchos mártires del tercer mundo en nuestros dias. En efecto, tanto aquéllos como éstos han sido asesinados por actuar proféticamente en la sociedad, más en concreto, por ponerse del lado de los oprimidos, de la justicia, del verdadero Dios.

El artículo está dividido en tres partes. En la primera se recogen las afirmaciones que el Nuevo Testamento hace frecuentemente sobre la persecución y muerte de los profetas. En la segunda, mostramos que ambas se basan realmente en lo que fue la vida y muerte de los profetas, tal como lo transmite el Antiguo Testamento. En la tercera se analizan las razones por las que fueron perseguidos y asesinados los profetas de Israel de modo que iluminen las persecuciones y muertes de los profelas-mártires de hoy.

Nos concentramos, pues, en la tradición sobre el destino de los profetas, sin analizar otras tradiciones sobre la muerte violenta del Antigo Testamento, como la tradición de los Macabeos, presentada más estrictamente como marticial, y la tradición del siervo de Yahveh, tradición específicarnente bíblica, que quizás no tiene parangón en otras tradiciones religiosas. Sobre esto último ya se publica otro artículo en este número. 


\section{1. "Persecución y muerte de los profetas" en el Nuevo Testamento}

En el Nuevo Testamento aparece claramente que persecución y muerte violenta pertenecen, como por naturaleza, al destino de los profetas. Con ello se recoge una larga tradición, a la que el Nuevo Testamento se remite en definitiva para esclarecer el destino de Jesús. Los profetas, en efecto, son quienes "de alguna manera anunciaban" los tiempos de Jesús, y por ello tampoco es de extrañar que —con su propia vida - preanunciasen su destino.

De hecho, el Nuevo Testamento, al buscar sentido a la muerte de Jesús, la comprende desde diversas perspectivas: a partir de la muerte del siervo (en un esquerna soteriológico) o según un plan divino de salvación (en un esquema histórico-salvífico). Pero la comprensión más antigua - y la más cercana a la realidad de los hechos- fue a partir del destino del profeta-mártir escalológico (en un esquema de contraste).

Veamos ahora los textos que hablan del destino de los profetas. La mayoría de ellos aparecen en los sinópticos y en boca de Jesús, con lo cual se expresa también la conciencia que Jesús tenía de que su vida corría peligro, precisamente, por ser profeta.

En el evangelio de Mateo, en los capítulos 21 al 23, estando ya en Jerusalén, Jesús cuenta dos parábolas sobre la suerte del enviado y pronuncia un discurso sobre la hipocresía de escribas y fariseos. En los tres textos se refiere a la suerte de los profetas. En la parábola de los labradores homicidas, recogida por los tres sinópticos (Mt 21, 33-46; Mc 12, 1-12; Lc 20, 9-19), el dueño de una vin̄a, que ha encargado de su cultivo a unos labradores, envía en el momento oportuno a sus siervos para recoger los frutos. Los enviados no son bien recibidos, sino que "los labradores agarraron a los siervos, y a unos les golpearon, a otros les mataron, $a$ otros les apedrearon..." (Mt 21,35). Al final, el dueño de la viña decide enviar a su propio hijo, pensando que a él sí le respetarán. La reacción de los labradores, sin embargo, es la de acabar con él para quedarse con la herencia (v. 39). La tesis es clara: los fariseos y los sacerdotes (a quienes se dirige la parábola, $c f r$. v. 45) siempre han rechazado a los enviados de Dios -los profetas- y están dispuestos a acabar ahora con el propio hijo.

Parecido es el mensaje de la parábola del banquete de bodas, de la que existen dos versiones: Lucas 14, 16-24 y Mateo 22, 1-14. En Lucas se dice simplemente que los invitados no quieren ir al banquete. El señor que les había invitado se enfada y envia a sus sirvientes a las calles para que hagan entrar al banquete a los pobres, lisiados, marginados. La lección es clara. Los primeros invitados (fariseos, saduceos y los oficialmente religiosos) no son dignos del banquete. En cambio, los marginados, los rechazados del pueblo y los paganos, están llamados a vivir en el banquete escatológico del que habían sido aparta-

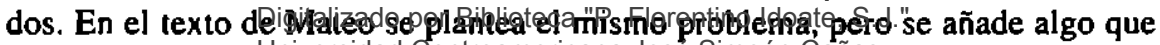


loca en direclo a nuestro tema. Cuando les avisan que ya está todo preparado, algunos de los invitados se excusan, pero de otros se dice que "agarraron a los siervos, los escarnecieron y los mataron" (Mt 22, 6).

Un tercer texto, en Mateo 23, es el discurso contra los escribas y fariseos. Tras las denuncias de los dos capítulos anteriores, Jesús pronuncia siete maldiciones directamente contra ellos, y concluyc con la durísima acusación de asesinato: matan a los profetas.

¡Serpientes, raza de víboras! ¿Cómo van a escapar a la condenación de la gehenna? Por eso, he aquí que yo envío a ustedes profetas, sabios y escribas: a unos los matarán y los crucificarán, a otros los azotarán en sus sinagogas y los perseguirán de ciudad en ciudad, para que caiga sobre ustedes toda la sangre inocente derramada sobre la tierra, desde la sangre del inocente Abel hasta la sangre de Zacarias, hijo de Baraquias, a quien ustedes mataron entre el santuario y el altar. Yo les aseguro: todo esto recaerá sobre esta generación (Mt 23, 33-36).

El discurso concluye apostrofando a Jerusalén: “iJerusalén, Jerusalén, que matas a los proferas y apedreas a los que re son enviados! Cuántas veces he querido reunir a tus hijos, como una gallina reúne a sus polluelos bajo las alas, y no has querido!" (Mt 23, 37).

El evangelio de Lucas recoge estos textos de Mateo en dos lugares separados. En Lucas 11, 47-51, Jesús recuerda el hecho lundamental del asesinato de los profetas, recrimina a los escribas y fariseos por su hipocresía, y los amenaza con que de ello tendrán que dar cuentas:

¡Ay de ustedes, porque edifican los sepulcros de los profesas que sus padres mataron! Por tanto, son testigos y están de acuerdo con las obras de sus padres; porque ellos los mataron y ustedes edifican. Por eso dijo la Sabiduría de Dios: les enviaré profetas y apóstoles, y a algunos los matarán y perseguirán, para que se pidan cuentas a esta generación de la sangre de todos los profetas derramada desde la creación del mundo, desde la sangre de Abel hasta la sangre de Zacarías, el que pereció entre el altar y el santuario. Sí, les aseguro que se pedirán cuentas a esta generación (Lc 11, 47-51).

En un segundo texto, en un contexto especifico de Lucas, algunos fariseos avisan a Jesús de que Herodes quiere matarlo, y aquél responde: "Conviene que hoy y mañana y pasado siga adelante, porque no cabe que un profeto perezca fuera de Jerusalén. ¿Jerusalén, Jerusalén!, que matas a los profetas y apedreas a los que son enviados" (Lc 13, 33-34).

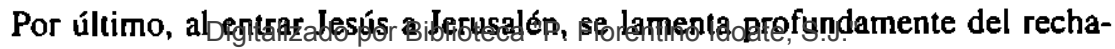

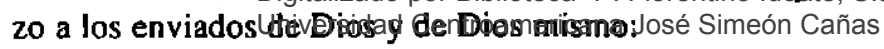


Al acercarse y ver la ciudad, lloró por ella, diciendo: ¡Si también tú conocieras en este día el mensaje de paz! Pero ahora ha quedado oculto a tus ojos. Porque vendrán días sobre ti, en que tus enemigos te rodearán de empalizadas, te ccrrarán y te apretarán por todas partes, y te estrellarán contra el suelo a li y a tus hijos que están dentro de ti, y no dejarán piedra sobre piedra, porque no has conocido el tiempo de iu visita ( $\mathrm{Lc} 19,41-44)$.

Jesús Ilora por Jerusalén, por las consecuencias que va a traer el haber rechazado al mismo Dios. "El tiempo de tu visita", en efecto, en terminología de los profetas de Israel significa el tiempo de la venida de Dios a juzgar a su pueblo.

El deslino violento de los profetas aparece también en otros escritos del Nuevo Testamento, lo cual quiere decir que en aquel tiempo era convicción arraigada, fruto de la sabiduría acumulada. Cuando Esteban es juzgado y condenado a muerte, dice: "¿A qué profeta no persiguieron sus padres? Ellos mataron a los que anunciaban de antemano la venida del justo, de aquel a quien ahora ustedes han traicionado y asesinado" (Hech 7, 52). En su primer escrito dice Pablo a los tesalonicenses: "también ustedes han sufrido de sus compatriotas las mismas cosas que ellos [los de Jerusalén] de parte de los judios; éstos son los que dieron muerte al Señor y a los profetas y los que nos han perseguido a nosotros" (1Tes 2, 14-15). Finalmente, el autor de la Carta a los Hebreos, al presentar los modelos de fe a lo largo de la historia, dice: "Otros soportaron burlas, azoles, y hasta cadenas y prisiones; apedreados, torturados, aserrados, muertos a espada; anduvieron errantes; faltos de todo; oprimidos y maltratados $(11,36-37)$-palabras que bien pueden aludir a los profetas.

La tradición de que los profetas - y el mismo Señor Jesús- fueron perseguidos, maltratados y asesinados recorre, pues, el Nuevo Testamento. Y es confirmada en tiempo de Jesús por lo ocurrido a Juan Bautista, quien es presentado como el precursor de Jesús. El Bautista anuncia, en medio del pueblo, que el reino de Dios está cerca, que el rey mesías está ya llegando y que es necesario vivir de un modo coherente para preparar dicha venida. Por otra parte, a cada persona y a cada grupo, comenzando por el rey, les conmina a la conversión. Juan Bautista acrúa, pues, como profeta, y esto le lleva a ser apresado y asesinado.

Jesús conoció la muerte violenta del Bautista a manos de Herodes, y le afectó de tal modo que, al conocer la noticia, se retiró a un lugar solitario (Mt 14, 13; Mc 6, 30). En la escena de la transfiguración, tal como la recoge Mateo, habla del Bautista como de Elías que ya ha regresado (Mt 17, 13), y se queja sobre todo de que "han hecho con él cuanto han querido". $Y$ añade que lo mismo harán con el Hijo del hombre (Mt 17, 12). En el destino de Juan Bautista ve Jesús -y los sinópticos- la confimación de la tesis de la tradición: el destino del profetangstdazpersequsión. 


\section{La muerte violenta de los profetas en el Antiguo Testamento}

Esta convicción del Nuevo Testamento tiene sus raíces, obviamente, en el Antiguo Testamento. Muy tempranamente fraguó la expresión de "dar muerte a los profetas". Así, en la tradición deuteronomista, Elías dice: "Ardo en celo por Yahveh, Dios Sebaoth, porque los israelitas te han abandonado... han pasado a espada a tus profetas; quedo yo solo y buscan mi vida para quitármela" (IRe 19, 10.14). Y en la tradición cronista, en un salmo propio de una ceremonia expiatoria, se lee: "Pero después, indóciles, se rebelaron contra ti, amojaron tu ley a sus espaldas, mataron a los profetas que les conjuraban a convertirse a ti" (Neh 9, 26). La muerte violenta aparece, pues, desde muy pronto como el destino de los profetas. Y además se explica el por qué: rebelarse contra la voluntad de Dios y matar a los profetas que exigen conversión van de la mano. A continuación vamos a ofrecer, en orden cronológico, algunos textos sobre el hecho en sí mismo, dejando para el apartado siguiente el análisis de las causas.

\section{1. "Los profetas anteriores"}

Vamos a analizar, en primer lugar, algunos textos de los libros que en la Biblia hebrea aparecen como "Profetas anteriores", en la llamada historia deuteronomista.

\section{"Un hombre de Dios" (1Reyes 13, 1-10)}

A la muerte de Salomón, su hijo Roboam intentó aumentar los impuestos y la opresión sobre los habitantes de la parte norte del país. $\mathrm{Y}$ ante las peticiones del pueblo de que aligerara el yugo, Roboam respondió altaneramente: "Mi dedo meñique es más grueso que los lomos de mi padre. Un yugo pesado les cargó mi padre, mas yo haré más pesado el yugo de ustedes; mi padre les azotaba con azoles, pero yo les azotaré con escorpiones" (1Re 12, 10b-11).

Los habitantes del norte se sublevaron entonces contra Roboam, se separaron del sur y elegieron como rey a Jeroboam, quien, durante los últimos años de Salomón, se habła refugiado en Egipto, porque aquél habia dado orden de caplura contra él. Jeroboam fue coronado como primer rey de la parte norte, Ilamada también Israel, y para evitar que el pueblo fuese a Jerusalén a dar culto a Yahveh -el que los había liberado de Egipto-, mandó construir varios santuarios y dos becerros de oro. Colocó uno en Betel y otro en Dan, y puso sacerdotes que se encargasen del culto, en Israel.

En esta situación, un hombre de Dios, de Judá, fue enviado por Yahveh y "llegó a Betel cuando Jeroboam estaba en pie sobre el altar para quemar incien-

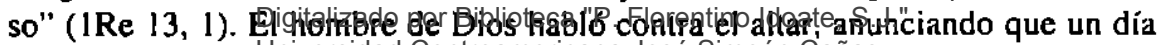
sería destruido. Pero la denuncra contra el laliso cuílo, en el preciso contexto 
histórico y político, era realmente una denuncia contra la acluación del rey. De ahí, la inmediata reacción de Jeroboam: la represión. En pocas palabras dice el texto lo que será el destino de "los hombres de Dios", de los profetas: "el rey extendió su mano desde encima del altar diciendo: préndanle" (1Re 13,4$)$.

\section{Elías (1Reyes 17-19)}

Un segundo profeta que sufrío persecución fue Elías. Gran parte de su aclividad profética tuvo lugar durante el reinado de Ajab, en Israel. Ocupa unos pocos capílulos del Primer Libro de los Reyes, pero aparece en ellos un enfrentamiento continuo entre profeta y realeza, y una persecución a mucrte contra Elías de parte de Ajab y de su esposa Jezabel. La causa fue que en el culto oficial a Yahveh se había introducido la concepción "baalista" del poder despótico y de la religión de la fecundidad. Contra esto habían reaccionado ya algunos profetas, y Ajab y Jezabel decidieron acabar con ellos. No lo consiguieron del todo gracias a que Abdías —de quien se dice que era temeroso de Yahveh-consiguió esconder y salvar a varios de ellos. El enfrentamiento y la persecución, sin embargo, habían comenzado. He aquí la secuencia.

Elías amenaza a Ajab con estas palabras: "Vive Yahveh, Dios de Israel, a quien sirvo. No habrá estos años rocío ni lluvia, más que cuando mi boca lo diga" ( $(\operatorname{Re} 17,1)$, e inmediatamente tiene que esconderse en el torrente de Kerit, al esle del Jordán. Tras un largo tiempo de sequía, Elías va al encuentro de Ajab, quien le recibe diciendo: “¿Eres tú, azote de Israel?”. Responde Elías: "No soy yo el azote de Israel, sino tú y la casa de tu padre, por haber abandonado a Yahveh y haber seguido a los Baales" ( $c f r .1$ Re 18, 17s). A continuación se narra el desafío que Elías hace a Jezabel y a los 450 profetas de Baal. Se reúnen en el monte Carmelo y allí se pone a prueba quién es el auténtico Dios de Israel. Los proletas de Baal no pueden conseguir, a pesar de todas sus artimañas, que su dios consuma la ofrenda sobre el altar. Elías, en cambio, con una sencilla oración lo consigue, y, además, la sequía se acaba. La victoria de Elías sobre los proletas - según la visión de la época de un Dios guerrero- parece darle derecho a acabar con los profetas de Baal, y asi lo hace (cfr. I Re 18, 20-46), lo cual provoca una nueva persecución contra él: "Envió Jezabel un mensajero a Elías diciendo: 'Que los dioses me hagan esto y me añadan esto otro si mañana a estas horas no he puesio tu alma igual que el alma de uno de ellos'" $(\operatorname{Re} 19,2)$. Elías tiene miedo y huye al desierto, deseando que Dios le quite la vida para dejar así de sufrir (cfr. $\mid \operatorname{Re} 19,3-4)$.

\section{Miqueas ben Yimlá (1Re 22)}

Aram había arrebatado a Israel Ramol de Galaad. Durante varios años, Israel

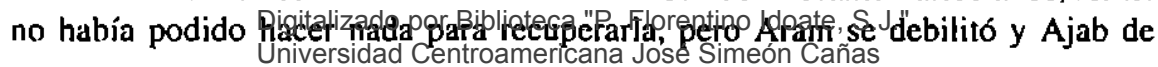


Israel creyó llegado el momento de reconquistar aquel territorio. Por otra parte. Ajab estaba en muy buenas relaciones con Josafal de Judá, y en una reunión tenida en territorio de Israel, Ajab propuso a Josafat ir juntos a la guerra contra Aram.

Josafal pidió a Ajab que se hiciera antes una consulta a los profetas para saber cuál era la voluntad de Yahveh. Se hizo la consulta y la corporación de profetas oficiales a sueldo animó a los dos reyes a que fuesen a conquistar Ramol de Galaad. El rey de Judá, sin embargo, quedó con fuertes dudas acerca de la honradez de aquellos funcionarios que, en definitiva, parecían aconsejar lo que el rey de Israel deseaba oír, y por ello preguntó si había algun profeta de fiar y pidió que se le consultase. Ajab reconoció que sí había uno, Miqueas ben Yimlá, pero añadió que lo aborrecía, porque siempre le profetizaba males. A pesar de ello, Josafat de Judá instó a Ajab de Israel a que lo fueran a buscar para consultarle y así fue.

Miqueas, por su parte, no hizo caso a quienes le pedían que aconsejase en la línea de los demás profetas, ya que Ajab quería ir a la guerra. Cuando se presentó ante los dos reyes, primero irónicamente y después de modo directo, les anunció que la empresa de conquistar Ramot de Galaad sería un fracaso, ya que era Dios mismo el que habla puesto una trampa a Ajab para que cayese ahí. Esta verdad - profética - contraria a la mentira de los profetas a sueldo, le costó cara a Miqueas. "Se acercó Sedecías, hijo de Kenaaná, y dio una bofetada a Miqueas en la mejilla" ( $\operatorname{Re} 22,24)$. El rey de Israel dio orden de prender a Miqueas, llevárselo al gobernador de la ciudad y al hijo del rey, meterlo en la cárcel, y racionarle el pan y el agua hasta que el rey Ajab volviera viclorioso.

\section{Miqueas el Morastí (Vidas de los profetas')}

Las Vidas de los proferas cuentan el caso de otro profeta, llamado Miqueas el Morastí, del que se dice que tuvo que vérselas con el rey Ajab y quien fue eliminado por Joram, su hijo y sucesor. Así lo dice escuetamente el texto: "Era de la tribu de Efraín. Después de dar mucho que hacer a Ajab, fue eliminado por su hijo Jorán, que lo despeño porque le echaba en cara las impiedades de sus antepasados" (Vidas de los profetas 6,1 ).

En este texto hay posiblemente un error en lo que se reliere al nombre del profeta y al contexto histórico. La obra apócrifa aparentemente identifica a este Miqueas el Morastí con el Miqueas de Moreset del libro de Miqueas. Sin embargo, por los datos que da (pertenece a la tribu de Efraín y se enfrenta a Ajab y a su hijo Joram), parece que se está refiriendo a Miqueas ben Yimlá, el que apare-

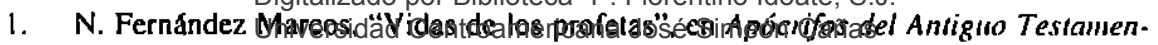
10 II. A. Diez Macho (ed.), Madrid, 1983, pp. 518-519. 
ce en 1 Reyes 22 y que ya se ha mencionado más arriba. En todo caso el error en el nombre no cambia nada la importancia del hecho en sí mismo: un profeta es perseguido y asesinado por enfrentarse al poder del rey. Los textos apócrifos comparten, pues, la misma convicción que los libros canónicos del Antiguo Testamento. Con frecuencia los profetas mueren asesinados porque molestan al poder —en aquel tiempo sobre todo al poder real- con sus denuncias y sus consejos.

Para terminar, mencionemos un último confliclo entre el rey Ococías y Elías tesbita. Ococías, hijo de Acab, tras sufrir un accidente -se habla caído de la celosía de su habitación-, no quiso consultar la voluntad de Yahveh a través del profeta Elías, sino que envió mensajeros para consultar a Baal Zebub, dios de Ecrón, en la zona filistea. Elías reaccionó con dureza, y ante la posibilidad de ser apresado, tomó sus propias medidas de seguridad. Finalmente, se presentó ante el rey para darle un duro mensaje cuando ya estuvo convencido de que el rey nada le podía hacer $(1 \operatorname{Re} 22,52-2 \operatorname{Re} 1,18)$.

\section{2. "Los profetas posteriores"}

Vamos a analizar ahora algunos textos de los libros de los "Profetas posteriores", un libro de la obra cronista, y las obras apócrifas ${ }^{2}$ de la Ascensión de Isaias y las Vidas de los profetas. En ellos se narra la persecución sufrida por Amós, Isalas, Miqueas de Moreset, Jeremías, Urías hijo de Semaías, Ezequiel y Zacarías hijo de Yehoyadá.

\section{Amós}

Amós fue un pequeño agricultor y ganadero de Tecoa, en el desierto de Judá. Por razones de mercado tuvo frecuente relación con la capital del reino del norte, en los últimos años del reinado de Jeroboam II, hacia el 750 a. C. Viendo la gran incoherencia entre la fe y la vida de la sociedad denunció duramente la injusticia, y lo hizo públicamente, aprovechando las grandes concentraciones en los santuarios, especialmente los de Betel y Guilgal. El libro de Amós recoge las fuertes denuncias y la dura reacción contra el profeta en los medios oficiales.

En Amós 7, 10-17 se cuenta que Amasías, sacerdote del santuario de Betel, denunció a aquél ante el rey Jeroboam y, además, se enfrentó directamente con

2. Puede extrañar el uso de obras apócrifas para fundamentar afirmaciones historicas. La razón es que los apócrifos están escritos en un ambiente en que se respira algo comúnmente aceptado. Pueden exagerar la realidad histórica, pero no falsearla. En el caso de los profetas, es significativo que en las obras apocrifas se repite siempre el hecho de que muchos de los profetas fueron perseguidos y asesinados. Este es el

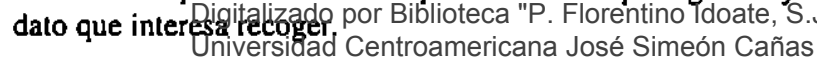


el profeta insultándolo y amenazándolo. Al rey le hizo llegar la siguiente denuncia: "Amós conspira contra ti en medio de la casa de Israel; ya no puede la tierra soportar todas sus palabras. Porque Amós anda diciendo: 'A espada morirá Jeroboam, e Israel será deportado de su suelo'” (Am 7, 10-11). Esto suponía acusar a Amós de alta traición, y con ello incitaba al rey a eliminarlo. Al propio Amós, Amasías lo insultó y lo amenazó diciendo: "'Vete, visionario; huye a la tierra de Judá; come allí tu pan y proletiza allí. Pero en Betel no has de seguir profetizando, porque es el santuario del rey y la Casa del reino"" (Am 7, 12-13).

En síntesis, la actuación profética de Amós en tomo al santuario de Betel muestra cómo reacciona el poder religioso, aliado del poder civil. En último término, busca la muerte o la expulsión del profeta. El texto de las Vidas de los profetas dice que, efectivamente, el profeta Amós sufrió una muerte violenta a manos del poder:

Era de Tecoa. Amasías lo golpeó a menudo; por fin, acabó con él su hijo, golpeándole con un vergajo en la sien. Todavia con vida llegó a su tierra, y a los pocos días murí y fue enterrado alli mismo (Vidas de los profetas $7,1-2$ )?.

\section{Isaías}

Isaías fue un personaje con gran autoridad moral. Sin embargo, sus mensajes proféticos no siempre fueron bien recibidos, sino que encontraron fuerte resistencia.

Un primer enfrentamiento ocurrí́ en el contexto de la trágica guerra que se desencadenó entre los aliados Israel-Aram-Filistea y Judá (en torno al año 735 a. C.). Isaías quería alimentar la fe y la confianza en Dios por parte del pueblo y del rey Acaz. Pero ni el rey ni la mayorla de sus cortesanos hicieron caso a sus mensajes, recogidos en el libro del Emmanuel, y en los que insiste en la confianza en Dios: Yahveh es "Dios con nosotros". Ante este rechazo Isaías se mantuvo firme y enfatizó la denuncia y el castigo. En Isaías 8, 14-15 presenta a Yahveh y a su santuario como "piedra de tropiezo y peña de escándalo, lazo y trampa para los moradores de Jerusalén", lugar donde "tropezarán muchos, caerán, se estrellarán y serán atrapados y presos". Y a continuación, en el v. 16 recibe el encargo de "envolver el testimonio, sellar la enseñanza entre sus disclpulos". Esto significa que la denuncia de Isaías debe quedar como testimonio para el futuro. $Y$ por lo que loca a nuestro tema, presupone indudablemente el ambiente de violencia, resistencia y cerrazón por parte de Judá a la buena nolicia que quería transmitir Isalas.

En una época posterior, aparece otro gran enfrentamiento de Isaías. El rey Ezequías sufre grandes presiones para que se alíe con Egipto en contra de Digitalizado por Biblioleca "P. Florentino Idoate, S.J."

3. Op. cit., p. 519.

Universidad Centroamericana José Simeón Cañas 
Asiria. La postura de Isaías es doble: conseguir la no alineación de Judá en ninguno de los dos bloques, y animar a Ezequías a llevar adelante una reforma religiosa y social, tan necesaria después de los años de gobierno de Acaz. Anle esto hay fuertes resistencias. Judá quicre acabar con la palabra profética e Isaías recibe de nuevo la orden de Yahveh de ponerla por escrito: "Ahora ven, escríbelo en una tablilla, grábalo en un libro, y que dure hasta el último día para testimonio hasta siempre" (Is 30,8 ). He aquí algunos fragmentos de las denuncias:

Que es un pueblo terco, criaturas hipocritas, hijos que no aceptan escuchar la instrucción de Yahveh; que han dicho a los videntes: "No vean"; y a los visionarios: "No vean para nosotros visiones verdaderas; háblennos cosas halagüeñas, contemplen ilusiones. Apártense del camino, desvíense de la ruta, déjennos en paz del Santo de Israel"... Por cuanto han rechazado ustedes esta palabra... por eso será para ustedes esta culpa como brecha ruinosa en una muralla, cuya quiebra sobrevendrá de un momento a otro... Pero ustedes no aceptaron, sino que dijeron: "No, huiremos a caballo". Pues bien, ¡huyan! Y "sobre rápidos carros montaremos". Pues bien, ¡rápidamente serán perseguidos! (Is 30, 9-17).

Isaías sufrí, pues, fuerte resistencia y rechazo. De ahí que sea muy verosímil lo que cuentan las Vidas de los profetas y la Ascensión de Isaías sobre la persecución y muerte de Isaías a manos del rey Manasés, sucesor Ezequlas. Los relatos son de fiar, pues consta históricamente la persecución contra la fe que provocó Manasés y la dependencia que dicho rey tuvo respecto al imperio asirio. De todo ello fue víctima Isaías. He aquí algunos fragmentos:

Era de Jerusalén. Murió en tiempos de Manasés, serrado en dos (Vidas de los profetas 1,1$)^{4}$.

Beliar (el jefe de los demonios) se estableció en el corazón de Manasés (el rey impío) y éste aserró a Isaías con una sierra de madera. Mientras era aserrado Isaías, Balkira (el Calso profeta), su delator, estaba allí y todos los falsos profetas asistían riendo y alegrándose por lo de Isaías. Riendo, Balkira le dijo a Isaías: "Confiesa lo siguiente: Yo he mentido en todas mis palabras y los caminos de Manasés son buenos y rectos como son buenos los caminos de Balkira y de los que están con él". (El falso profeta) habló así mientras Isaías empezaba a ser aserrado. Pero Isaías estaba en una visión del señor; sus ojos estaban abiertos, pero sin ver (a sus verdugos). Balkira continuó: "Di lo que te he dicho y yo cambiaré su corazón; obligaré a Manasés, a los príncipes de Judá, al pueblo y a todo Jerusalén a postrarse ante ti". Isaías respondio: "Si pronuncio alguna palabra será ésta: ¡Sean execrados y maldi-

4. bid., p. 513. 
tos tú, todas tus potencias y toda tu casa! Pues tú no puedes tomar nada más que la piel de mi cuerpo".

Se apoderaron de Isaías, hijo de Amós, y lo aserraron con una sierra de madera. Manasés, Balkira, los falsos profetas, los príncipes y el pueblo, todos estaban en pie y miraban. Pues bien, antes de ser aserrado, Isaías había dicho a los (verdaderos) profetas que estaban con él: "Vayan a refugiarse en la región de Tíro y de Sidón, pues sólo para mí ha mezclado Dios la copa". Y mientras era aserrado, Isaías no gritó ni lloró, sino que su boca habló al Espíritu Santo hasta que fue partido en dos. Esto es lo que Beliar (el jefe de los demonios) hizo con Isaías por manos de Balkira y por manos de Manasés (Ascensión de /saias 5,1-15).

\section{Jeremías}

Jeremías es, según la tradición y el texto canónico, el profeta que sufrió mayores persecuciones, hasta la muerte, por parte de las autoridades del reino de Judá. Es cierto que en su primera actividad entre los años 628 a 622 a. C., cuando profetizó ante sus compatriotas de Anatol - su pueblo natal- les prometió una nueva esperanza si se convertían, y por ello su actividad profética fue más bien tranquila y aun gratificante. Pero a partir de su segunda actividad, en el año 609 a. C., y hasta el día de su muerte en Egipto, hacia el año 580 a. C., se fueron sucediendo cada vez con mayor agresividad incomprensiones, difamaciones, persecuciones, torturas, órdenes de captura contra él. Todo ello por fídelidad a Yahveh, quien lo enviaba a profetizar.

Efectivamente, al comienzo de reinado de Joaquín I (Jer 26, 1) comenzaron las fuertes denuncias de Jeremías en el templo y contra el templo, y el apresamiento e intento de linchamiento no se hicieron esperar. Fue llevado a juicio y los sacerdotes y profetas del templo pidieron a los jefes y a todo el pueblo su condena a muerte. Gracias a una hábil defensa de unos ancianos, amigos de la familia de Jeremías, finalmente salió absuelto, y no fue ejecutado tal como pedían sus enemigos. En el mismo capítulo (26, 20-23), sin embargo, se narra que el profeta Urías, compañero de Jeremías, fue perseguido por orden del rey por hablar como hablaba Jeremías. A causa de la persecución, huyó a Egipto, pero, dada la alianza entre el faraón de Egipto y el rey de Judá, éste pidió a aquél que le entregase a Urías. El faraón así lo hizo y Joaquín I lo asesinó con sus propias manos.

Jeremías salí libre de aquel primer peligro, pero prosiguio la persecución. Después de la acción simbólica de la vasija rota —que expresaba desgracias

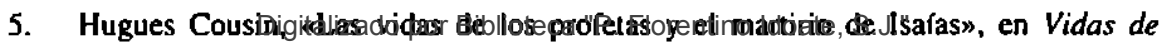

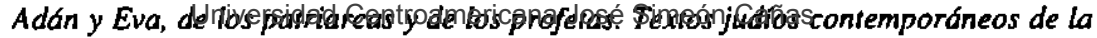
era cristiana, Documentos en tomo a la Biblia, 3, Navarra, 1981, pp. 92-93. 
para Judá-, fue apresado por el jefe de la policía del templo, torturado y conminado a no seguir hablando y actuando como hasta entonces $(19,1-20,6)$.

Más adelante, Jeremías dictó a Baruk unas palabras de amenaza contra Judá y contra Jerusalén, y le pidió que las leyera en público. El escrito llegó a manos del rey Joaquín. Este. a medida que lo iba leyendo, lo iba quemando, como para sofocar mágicamente los efectos de las palabras escritas, y a continuación dio "orden de búsqueda y caplura" contra Jeremías y Baruk para acabar con ellos. Tuvieron que permanecer ocultos hasta que el rey murió a manos de Nabucodonosor, emperador de Babilonia, cuando éste se apoderó de Jerusalén, y ambos fueron liberados por él (cfr. Jer 36).

A partir del año 593 a. C., ahora con Sedecías en el trono de Jerusalén, volvieron a resurgir los grandes enfrentamientos de Jeremías con el poder. El primer gran conflicto, en 593, tuvo lugar entre Jeremías y otro profeta llamado Jananías ( $c f r$. Jer 27-28). El contexto fue el siguiente. Habían llegado a Jerusalén embajadores de los países limírrofes para hacer una alianza con Egipto, en contra del imperio babilónico. Jeremías se presentó, entonces, por la ciudad con un yugo al cuello, acción simbólica con la que quería desmentir a Jananías, quien iba pregonando que el yugo de Babilonia ya estaba roto. Jeremías no lo pensaba así y llamó al realismo, pidiendo al pueblo que no se rebelasen contra Babilonia, pues les iba a ir mal. El enfrentamiento con Jananías fue durísimo y humillante para Jeremías, quien quedó práclicamente desautorizado ante todo el pueblo.

También tuvo fuertes conflictos -por carta- con algunos de los profetas del templo que habian sido deportados con el pueblo a Babilonia, en el año 598 a. C. (cfr. Jr 29), hasta el punto de que éstos pidieron por escrito al jefe de la policía del templo de Jerusalén que encarcelase a Jeremías ya que, según ellos, "estaba loco". Lo peor de todo es que Jeremías no consiguió evitar la rebelión, y la llegada de los ejércitos babilonios a las puertas de Jerusalén no se hizo esperar. En todo el tiempo que duró el ataque y asedio de Jerusalén (589 a 587 a. C.), las palabras y los hechos de Jeremías fueron mal interpretados, sobre todo por muchos de los ministros del rey Sedecías, lo cual llevó a lo que se puede llamar la gran persecución contra Jeremías. Traternos de recomponer la secuencia, tal como se nos narra sobre todo en los capílulos 34. 37-39, dentro de cierto desorden, según el texto actual.

Comienza el asedio de Jerusalén (Jer 39, 1). Sedecías envía una comisión a Jeremías para consultarle y pedir un milagro, pero Jeremías anuncia que "Jerusalén caerá y que es mejor que se entreguen" (Jer 21, 1-10). Los amos dejan en libertad a los esclavos para congraciarse con Dios y porque además, ya no los pueden alimentar; se pide la intercesión de Jeremías; el faraón egipcio viene contra Babilonia; los babilonios levantan el asedio; los señores vuelven a recu-

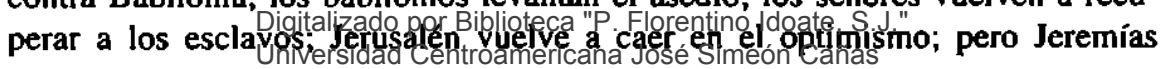


afirma que "Egipło volverá a su tierra y Babilonia les dominara" (Jer 34, 8-22; 37, 3-10). Jeremías intenta ir a su pueblo a comprar un campo, aprovechando la retirada de los babilonios; es acusado de quererse pasar al enemigo; es torturado y encerrado en los calabozos del escriba Jonalán (Jer 37, 11-16).

Nabucodonosor hace retirar a los egipcios y vuelve contra Jerusalén; Sedecías manda traer a Jeremías para consultarle; Jeremfas le dice que "no haga caso de los profetas, que va a ser entregado en manos de Babilonia" y le pide que "le haga la gracia de ponerle en una prisión más suave"; es trasladado al patio de la guardia (Jer 37, 17-21). Desde allí anuncia que caerá la ciudad y recomienda que se entreguen; algunos jefes consiguen del rey la pena de muerte bajo la acusación de alta traición contra el pueblo; es echado a la cisterna fangosa; cuando ya está a punto de morir, un esclavo del rey consigue el indulto y cambio de pena; lo sacan y lo dejan de nuevo en el patio de la guardia (Jer $38,1-13$ ). Jeremías pronuncia palabras de salvación para el esclavo del rey que le ha salvado y palabras de ruina contra la ciudad (Jer 39, 15-18).

Sedecías vuelve a consultar a Jeremías a escondidas; éste le aconseja que "se entregue, pues, si no, acontecerá la ruina total" y le asegura que "nadie se burlará de él por entregarse"; aconsejado por Sedecías, Jeremías miente a los ministros cuando le preguntan sobre el tema de la entrevista (Jer 38, 14-28). En el momento más crítico del asedio, Jeremías compra ante notario un campo familiar y asegura que "se volverán a comprar casas y campos"; hace nuevas promesas de restauración (Jer 32; 33, 1-13). Cae Jerusalén, el templo es destruido, vuelve a darse una deportación a Babilonia, los hijos del rey son ajusticiados, el rey es llevado preso a Babilonia, Jeremías es liberado. Bajo el gobernador Godolías queda un grupo de campesinos en Judá, Jeremías se queda con ellos (Jer 39, 2-14).

La secuencia es impresionante, pero las persecuciones no acabaron ahí. El gobernador Godolías es asesinado y entonces muchos judfos de Judá temen las represalias y quieren huir a Egipto; intentan que el profeta se muestre partidario de esta decisión. Ante la negativa de Jeremías, optan por ir a Egipto y llevarse al profeta contra su voluntad; ya en Egipto, no quieren aceptar las críticas y denuncias que el profeta les hace (Jer 40-44). Por esta razón, quizás, las Vidas de los profetas narran la muerte violenta de Jeremías a manos de sus compatriolas, quienes to apedrearon. Asl dice el texto: "Era de Anatot y murí en Tafne de Egiplo, apedreado por el pueblo" (Vidas de los profetas 2, 1)

\section{Ezequiel}

Ezequiel, sacerdote de Jerusalén, fue llamado a profetizar en Babilonia a los

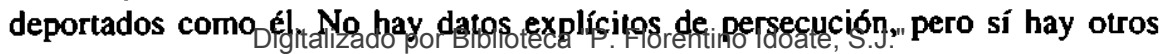
Universidad Centroamericana José Simeón Cañas

6. Ibid., pp. 5/4-516. 
que, indirectamente, hacen pensar en una fuerte oposición al profeta. Entre éstos podemos mencionar los capítulos en que Ezequiel recuerda al pueblo su infidelidad y cerrazón (Ez $8 ; 11 ; 16 ; 20 ; 23)$, su desautorización de aquellos profelas que hablan de seguridad y falsas esperanzas (Ez 13), del anuncio del asedio y la caída de Jerusalén (Ez 4-5). Estos y otros textos muestran que Judá se opuso con fuerza al profeta, al menos en su primer momento de actividad entre los años 593 y 587, cuando todavía los judíos -lambién los exiliados en Babiloniamantenían la esperanza, pues seguía en pie Jerusalén, el templo y la monarquía davídica.

Hay tres textos, sin embargo, que expresan con claridad la oposición: Ezequiel 3, 16-21; 14, 12-23; 18. En ellos Dios comunica al profeta que cada persona es responsable de sus propios aclos y que le irá según hayan sido sus obras justas o injustas. Añade Dios que lo que le toca al profeta es llamar a cada persona a salir de su injusticia y vivir en plena justicia, y que, si el profeta cumple con su obligación de hablar y los que le deberían escuchar no lo hacen, el profeta no es responsable del mal fin en que acaban aquéllos; sólo será responsable si no ha hablado cuando tenla que hablar, y por tanto, no ha ayudado a que se dé conversión en el pueblo. Estas palabras sobre la responsabilidad personal -también la del profeta- presuponen que Ezequiel, aun añadiendo muchos actos simbólicos, no tuvo éxito. Echó en cara la infidelidad de Judá y llamó a conversión, pero los judíos en el exilio se cerraron y no quisieron escucharlo. La tradición judía recogió la persecución a Ezequiel. Resultó tan molesto a sus compatriotas en Babilonia que acabaron matándolo.

Procede de la tierra de Sarira, del grupo sacerdotal, y murió en el país de los caldeos durante el destierro, después de haber profetizado muchas cosas a los de Judea. Allí mismo le asesinó el jefe de los israelitas por echarle en cara la veneración de los ídolos... Uno de entre ellos [un israelita] fue el que lo eliminó, pues se había opuesto a él [a Ezequiel] durante todos los días de su vida (Vidas de los profetas $3,1-2.20$ ) ${ }^{7}$.

\section{Zacarías}

El último profeta que, según el Antiguo Testamento murió asesinado, fue Zacarías, hijo de Yehoyadá, posiblemente el mismo que Jesús menciona en Mateo 23, 35 como hemos visto más arriba". Su muerte es mencionada en el texto canónico y en los apócrilos.

7. Ibid., pp. 516-517.

8. En el evangelio de Mateo aparece como hijo de Baraqulas ( $c f r$. Mt 23, 35), mientras que en 2Crónicas 24, 20-22 como hijo de Yehoyadá. La Biblia de Jerusalén, en su edición cotalmente revisada y aumentada, Desclée de Brouwer, Bilbao, 1975. p.

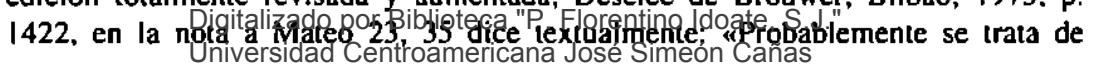


Entonces el espíritu de Dios revistió a Zacarías, hijo del sacerdote Yehoyadá, que, presentándose delante del pueblo les dijo: "Así dice Dios: ¿Por qué traspasan los mandamientos de Yahveh? No tendrán éxito: pues por haber abandonado a Yahveh, él les abandonará a ustedes". Pero ellos conspiraron contra él, y por mandato del rey le apedrearon en el atrio de la casa de Yahveh. Pues el rey Joás no se acordó del amor que le había tenido Yehoyadá, padre de Zacarías, sino que mató a su hijo que exclamó al morir: ¡Véalo Yahveh y exija cuentas! (2Cro 24, 20-22).

De Jerusalén, hijo de Yehoyadá el sacerdote, al que asesinó Joás, rey de Judá, cerca del altar. La casa de David derramó su sangre, en medio del santuario, sobre el patio. Los sacerdotes lo agarraron y lo enterraron junto con su padre (Vida de los profetas 21,1 )".

\section{Las razones de la muerte violenta de los profetas}

El recorrido que acabamos de hacer es impresionante, pero no es casual, sino que es inherente a la actividad profélica. Nos queda por ver, pues, las razones, to cual es importante para iluminar persecuciones y muertes violentas en la actualidad.

Una primera lectura de los textos podría llevar a la conclusión de que la razón de la muerte de los profetas pertenece al ámbito puramente religioso: su defensa de la le en Yahveh y sus fuertes alaques a la religión de los Baales. Esto es cierto, pero hay que entenderlo bien, pues, leído en sentido restrictivo, ello signilicaría que los profetas fueron matados simplemente por confesar una fe, distinta a la que, en un momento dado, querían reyes, falsos profetas y poderosos. Si así fuera, su muerte los convertiría en "mártires" y "testigos" de un delerminado credo, pero no de una fe con contenidos en favor de la justicia, la compasión, la verdad... Y de tal manera sería restrictivo que, como ocurre hoy, no podrían ser Ilamados "mártires" personas como Gandhi, Martin Luther King, Monseñor Romero, Monseñor Gerardi, y un largo etcétera de hombres y mujeres, que han entregado su vida por la defensa de la vida digna y justa de todos.

Para esclarecer, pues, las razones de la muerte de los profetas vamos a comenzar de otra manera, aparentemente sencilla, pero más iluminadora. "Se mata a quien estorba", decía Monseñor Romero ${ }^{10}$, y los profetas de Israel estorbaron

Zacarfas de 2 Crónicas 24, 20-22. Su asesinato es el último que se refiere en la Biblia (2Crónicas es el último libro del canon judío), mientras que el de Abel, Génesis 4, 8, es el primero. 'Hijo de Baraquias' procede quizás de la confusión con algún olro Zacarías, $c f r$. Is 8, 2 (LXX); Zac I, 1. O acaso estas palabras sean glosa del copista».

9. $\quad$ Ibíd., p. 524. Digitalizado por Biblioteca "P. Florentino Idoate, S.J."

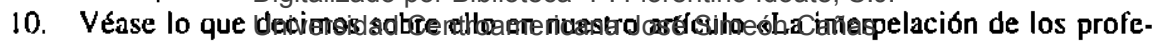
tas de ayer y de hoy", Revista Latinoamericana de Teología 24 (1991), pp. 254ss. 
grandemente. Ese estorbo aparece, normalmente, en los enfrentamientos con los poderosos: los reyes, sus profetas y sacerdotes, y con los acumuladores de la riqueza y los jueces a su servicio. En ese enfrentamiento los profetas les echan en cara sus crímenes, contrarios a la voluntad de Yahveh, les anuncian castigos en nombre de Dios y les exigen la conversión. Eso es lo que estorba, lo que molesta y no complace al rey, como dicen los falsos profetas cortesanos.

En ese sentido si se puede decir que los profetas son asesinados porque, al defender la religión de Yahveh, molestan a los veneradores de religiones que sirven a los ídolos. Y éstos, como lo puso en claro von Rad, no son realidades sólo ni fundamentalmente del ámbito religioso, sino histórico. Como lo hemos analizado en otro lugar" ", los profetas denuncian cinco formas de idolatría histórica: (1) la religión como privilegio o seguridad, (2) la monarquía y el poder, (3) las superpotencias, (4) la confianza en los pactos y en las armas, y (5) la injusticia y ambición de riqueza. Entendida así la religión idolátrica y entendida la religión de Yahveh como práctica de la justicia a los oprimidos y confianza sólo en él, se pueden comprender las razones históricas de la muerte de los profetas, parecidas, muchas de ellas, a las de los profetas actuales. Veámoslo, recorriendo de nuevo, brevemente, la historia que hemos visto en el apartado anterior.

En el texto de IReyes 13,1-10, "un hombre de Dios" denuncia el uso político que Jeroboam I hacía de la religión, hasta tal punto que había construido varios santuarios en el norte para evitar que el pueblo fuese a dar culto a Yahveh en el sur, en Jerusalén. La persecución contra este "hombre de Dios" liene, pues, su origen, en sus ataques al rey, porque estaba fundamentando su política en una religión manipulada, en pro de sus propios intereses y no de los del pueblo.

La persecución a muerte de Elías, el gran defensor de la fe en Yahveh, se debe a su enfrentamiento con los reyes Ajab y Jezabel por seguir éstos un patrón de conducta basado en la concepción "baalista" de la religion de la fecundidad y del poder despótico que se había ido introduciendo en Israel. En formulación religiosa, la persecución se debe a lo siguiente: Elías acusa a Ajab de "haber abandonado a Yahveh y haber seguido a los Baales" (cfr. IRe 18, 1-19); triunfa sobre los profetas de Baal en el monte Carmelo (cfr. IRe 18, 20-46); denuncia que "los israelitas han abandonado tu alianza, han derribado tus altares y han pasado a espada a tus profetas; quedo yo solo y buscan mi vida para quitárme-

11. Ibid., pp. 255-277. Véanse también otros artículos nuestros sobre temas semejantes, "Crítica profélica a los imperialismos y a la religión nacionalista de Israel», Revista Latinoamericana de Teología 95 (1985) pp. 95-1 11; «Monseñor Romero, los profetas de Israel y los ídolos: la religion, las potencias extranjeras, las armas y el podem, Revista Latinoameicana de Teología 42 (1997) pp.173-192; «Monseñor Romero y los profetas de Israel: el ídolo de la riqueza y el Dios de vidan, Revista

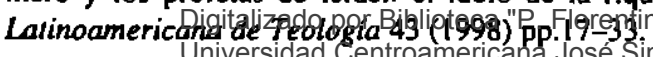


la" (cfr. 1Re 19, 10.14). Visto desde las consecuencias históricas, la razón de la persecución es que Elías se opuso a una práctica "baalista" de la fe en Yahveh, según la cual la relación con Dios puede ser manipulada por medio de los actos de culto (como la prostitución sagrada y el sacrificio del primogénito) con los que se "obliga" a la divinidad a fecundar la tierra y el rey adquiere derechos despóticos sobre sus súbditos. Esto es lo que denunció Elías, y de ahf la persecución.

En el enfrentamiento de Elías con Ocozías, hijo de Ajab (IRe 22, 52 - $2 \operatorname{Re}$ 1,18 ), aquél acusa al rey de no ponerse en manos de la voluntad de Dios y de preferir obedecer a otros dioses como Baal Zebub, dios de Ecrón, en la zona filistea. La razón es que esos dioses son menos exigentes y lo comprometen menos en su actuación como rey.

Miqueas ben Yimló (cfr. 1Re 22) fue perseguido porque se opuso en nombre de Yahveh a la decisión de Ajab de conquistar militarmente el territorio de Galaad, utilizando la ideologra de la "guerra santa". Miqueas acusó de mentirosos y aprovechados a los profetas de la corte, que favorecían la empresa, con lo cual estaba desenmascarando la manipulación de Yahveh: presentar la propia voluntad como voluntad de Dios, dejarse guiar por sus propios intereses, en contra de lo que Dios realmente quiere para su pueblo. Las Vidas de los profetas lo dicen con claridad: "(Miqueas) después de dar mucho que hacer a Ajab, fue eliminado por su hijo Jorán, que lo despeño porque le echaba en cara las impiedades de sus antepasados" (Vidas de los profesas 6,1$)^{12}$.

Amós fue perseguido por el rey Jeroboam Il y Amasías, el sacerdote de Betel, a causa de las denuncias que hizo contra la hipocresía de la gente poderosa de Israel: hablaban mucho y daban culto a Yahveh, el Dios liberador de Egipto, el que les habra elegido, pero con sus obras atentaban contra la fraternidad, contra la justicia, contra la solidaridad hacia los más pobres. Para quienes detentaban el poder, las denuncias y amenazas del profeta desestabilizaban la situación, aparentemente buena y beneficiosa para toda la sociedad. Amos dej6 en claro la relación entre pecados contra Dios y pecados contra el pueblo, y eso originó la persecución y, posiblemente, su muerte violenta.

Isaías fue perseguido por exigir a Judá que volviese a fundamentar su existencia como pueblo en la confianza en Dios y no en una religiosidad que pensase poder forzar a Dios en su favor, ni en el apoyo de fdolos, como lo eran las armas asirias o de cualquier otro imperio. Los apocrifos lo dicen con precisión: "Balkira (el falso profeta), su delator, estaba allí y todos los falsos profetas asistían riendo..., y Balkira le dijo a Isafas: 'Confiesa lo siguiente: Yo he mentido en todas mis palabras y los caminos de Manasés son buenos y rectos como

12. N. Fernández Marcos, op. cit., pp. 518-519. 
son buenos los caminos de Balkira y de los que están con él'" (Ascensión de Isaías 5, 1-15) ${ }^{13}$. Según los apócrilos, pues, Isaías se mantuvo firme en acusar al rey y a los falsos profetas de obrar con maldad y no aceptar la conversión.

Jeremias es el profeta del que más se detallan las muchas incomprensiones, difamaciones, persecuciones, torturas y órdenes de captura que tuvo que sufrir. Veamos ahora las razones.

La causa de la primera gran persecución fueron las fuertes denuncias en el templo y contra el templo, en el año 609 a. C., al inicio del reinado de Joaquín I. Lo que enervó a los poderes civil y religioso de Judá fue que, con ello, Jeremías socavaba los fundamentos de la alianza existente entre ambos poderes, desenmascaraba la hipocresía de quienes cometían toda clase de atropellos e injusticias y tranquilizaban sus conciencias en el templo de Jerusalén, como si éste les fuera a salvar y no la conversión sincera al Dios Yahveh, presente en la vida. Para colmo, el profeta se había atrevido a utilizar un argumento histórico: también en el reino del norte hablan tenido un gran santuario, el de Silo, y de nada les había servido. Además, sólo comparar el reino de Judá con el de Israel, el templo de Jerusalén con el santuario de Silo, era una gran osadía. Estas mismas denuncias fueron las que llevaron a la muerte a otro profeta compañero de Jeremías, Urías (cfr. Jr 26, 20-23).

En el episodio de la vasija rola, la razón para el encarcelamiento y tortura (Jer 19, 1 - 20,6) consiste en que Jeremías se atrevió a anunciar la destrucción del país y de su capital, Jerusalén, pues de nada sirven chauvinismos y nacionalismos si no van acompañados por una auténtica unión, en fraternidad, en torno a Yahveh. Y estas mismas amenazas contra Judá y Jerusalén, en este caso por escrito, son la causa de la orden de "búsqueda y captura" contra Jeremías y Baruk (Jer 36).

El enfrentamiento de Jeremías con los falsos profetas, a partir del año 593 a. C., se debió a que desaconsejó la rebelión contra Babilonia que apoyaban aquéllos, pues el yugo estaba a punto de ser quebrado. Pero Jeremías se atreví́ a decir que tal yugo era de hierro y que por el momento debían esperar y prepararse para el momento oportuno en que Babilonia estuviese para caer. Se atrevió también a decir que los profetas hablaban desde sus propios intereses y estaban mintiendo, y que todo lo que se basa en la falsedad sólo puede llevar a la ruina (cfr. Jr $27-29$ ).

La persecución arreció durante el ataque y asedio babilonios de Jerusalén (entre los años 589 y 587 a. C.), que siguieron a la rebelión del rey Sedecías, a

13. Hugues Cousin. "Las vidas de los profetas y el martirio de Isalas", en Vidas de Adán y Eva, de los patriarcas y de los profelas. Texios judíos contemporáneos de la

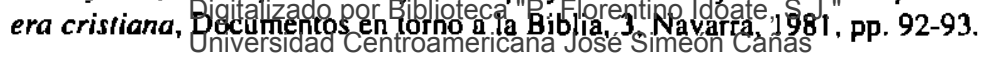


pesar de los consejos de Jeremías, y la razón profunda fue la postura de Jercmías, que, en aquel momento, era la de negociar. Esto fue malinterprelado como si Jeremías tuviese intereses probabilonios, sin entender que tal postura estaba motivada por un interés real por el pueblo que sufriría grandemente, si la guerra seguía adelante.

Finalmente, tras el asesinato de Godolías, Jeremías fue perseguido porque algunos judíos querían is a refugiarse a Egipto, pero Jeremías no lo apoyó. Entonces lo privaron de libertad y lo llevaron a Egipto, práclicamente secuestrado. Allí le quitaron la vida por decir su palabra honrada, desde la experiencia de Dios, sobre la conducta de sus compatriotas (cfr. Jr 40 - 44; Vidas de los profetas 2,1$)^{14}$.

La persecución contra Ezequiel se debió a las continuas Ilamadas a la conversión, a desenmascarar la inutilidad de las falsas esperanzas propiciadas por los profetas que decían falsedad de acuerdo a sus propios intereses, a su llamada a volver a reconocer a Yahveh presente en la historia y aceptar con confianza su voluntad (cfr. Ez 8; 11; 16; 20; 23; Ez 13; Ez 4 - 5; Ez 3, 16-21; 14, 12-23; 18; Vidas de los profetas $3,1-2.20)^{15}$.

Zacarias, hijo de Yehoyadá fue asesinado en el atrio del templo porque acusaba al pueblo y a los jefes de Israel de traspasar los mandamientos de Yahveh y les anunciaba que no tendrían éxito, ya que ellos habían abandonado a Yahveh (2Cro 24, 20-22; cfr. Vida de los profetas 21, 1) ${ }^{1 \mathrm{n}}$. Esto mismo, en forma generalizada, se dice en Nehemías 9,26 , en el contexto de una ceremonia expiatoria: "Indóciles, se rebelaron contra ti, arrojaron tu ley a sus espaldas, mataron a los profetas que les conjuraban a convertirse a ti; grandes desprecios te hicieron". La razón de la persecución y muerte de los profetas es, en definitiva, que se dedicaron a recordar la necesidad de conversión y de cumplir la voluntad de Dios.

\section{Conclusión}

Como hemos visto, los profetas bíblicos fueron perseguidos y asesinados. La razón, dicho en forma de tesis, fue por desenmascarar el abandono de Yahveh y el seguimiento de los Baales. Pero, al analizar los textos con cuidado, es claro que para los profetas el ámbito de lo religioso no existe por sí mismo, sino que se expresa en ámbitos históricos. De ahí que los profelas siempre subrayaron la unidad existente entre el abandono de Yahveh-seguimiento de los Baales y las consecuencias-repercusiones sociales.

\footnotetext{
14. Ibid., pp. 514-51 Gittalizado por Biblioteca "P. Florentino Idoate, S.J."

I5. Ibid., pp. 516-5Jhiversidad Centroamericana José Simeón Cañas

16. Ibid., p. 524.
} 
En la mente y en la palabra de los profetas, seguir a los Baales significaba aceptar una sociedad en la que el poder del rey era despótico; intentar la manipulación cúltica del Dios Yahveh; sacrificar en el altar de la divinidad la vida de los pobres; ocultar la injusticia judicial y social, reprimir a quienes querían desenmascarar la falsa seguridad, basada en la teología de la elección y en la ideología de la guerra santa; profesar un nacionalismo a ultranza, que llevaba a un rechazo radical de los demás pueblos; dejarse llevar por un triunfalismo alienante, que no contemplaba la realidad de los empobrecidos; en último término, rechazar el estilo de actuar y de ser de Yahveh, descubierto en la experiencia histórica de su presencia, que no es otro que un estilo liberador, justo, gratuito, libre, misericordioso, compasivo, tierno, amoroso, y no vivir como personas y como pueblo de acuerdo a este estilo de Yahveh. Estas eran las diferentes formas en que se concretaba el abandono de Yahveh, el seguimiento de los Baales y la idolatría.

En lenguaje posterior, se puede decir que los profetas fueron perseguidos y asesinados por dar "testimonio" de Yahveh, pero más primigeniamente, por " $\mathrm{f}_{1}$ delidad" a la misión que él les había encomendado. Esa misión consistió teologalmente, en poner la confianza sólo en él. Históricamente, consistió en defender al pueblo oprimido, "mi pueblo" como dice Yahveh, de la injusticia de los opresores.

Por estas o semejantes razones siguen siendo perseguidos y asesinados los profetas de nuestro tiempo, cuya lista está todavía por hacer y es interminable. 